\title{
Assessment of Knowledge, Attitudes and Practices Related to Contraceptive Use among Teenagers in High Schools and Colleges in Dakar, Senegal
}

\author{
Ndèye Marème Sougou1,2*, Oumar Bassoum 1,2, Ndèye Yacine Seck1, Mbathio Diop"1, \\ Jean Baptiste Diouf ${ }^{3}$, Mamadou Makhtar Mbacké Lèye ${ }^{1,2}$, Anta Tal-Dia, ${ }^{1,2}$ \\ ${ }^{1}$ Department of Preventive Medicine and Public Health, Faculty of Medicine, University Cheikh Anta Diop, Dakar, Senegal \\ ${ }^{2}$ Institute of Health Development, University Cheikh Anta Diop, Dakar, Senegal \\ ${ }^{3}$ Hospital of Roi Baudoin, Ministry of Health, Dakar, Senegal \\ Email: *nmsougou@hotmail.com
}

How to cite this paper: Sougou, N.M., Bassoum, O., Seck, N.Y., Diop, M., Diouf, J.B., Lèye, M.M.M. and Tal-Dia, A. (2019) Assessment of Knowledge, Attitudes and Practices Related to Contraceptive Use among Teenagers in High Schools and Colleges in Dakar, Senegal. Advances in Sexual Medicine, 9, 29-39.

https://doi.org/10.4236/asm.2019.93003

Received: March 19, 2019

Accepted: May 18, 2019

Published: May 21, 2019

Copyright $\odot 2019$ by author(s) and Scientific Research Publishing Inc. This work is licensed under the Creative Commons Attribution International License (CC BY 4.0).

http://creativecommons.org/licenses/by/4.0/

\begin{abstract}
Introduction: In Senegal, adolescents aged 10 to 19 years represent $22.9 \%$ of the total population. The unmet need for contraception in this part of the population remains high despite the health interventions implemented to promote their sexual health. The aim of this study is to analyze the practice of modern contraception in schools in Dakar high schools in Senegal during the year 2018. Methods: A cross-sectional study was conducted in high schools and colleges in Dakar from March 1 to April 30, 2018. This study involved 452 students. This was a self-administration of the questionnaires. After univaried and bivaried analyses, a multivariate logistic analysis identified the factors associated with students' use of modern contraception. Results: The prevalence of modern contraceptive use among students is $8.84 \%$. Factors associated with the use of modern contraceptive methods among students were age over 18 years (AR: 4.7, 95\% CI [1.02 - 22.5]), male sex (AR: 27.8, 95\% CI [6.8 - 100.0]), secondary school level (AR: 10.6, 95\% CI [2.1 - 53.0]), access to a youth socio-educational home (AR: 3.9, 95\% CI [1.1 - 14.9]) and having a child (AR: 25.6, 95\% CI [2.2 - 100.0]). Conclusion: Our results concluded that modern contraceptive needs were better met among older male students, those who had an unfortunate experience of unwanted pregnancy and those attending school's youth socio-educational homes. This suggests shortcomings in the promotion of sexual health among younger students, particularly those in the secondary grades.
\end{abstract}




\section{Keywords}

Schooling, Modern Contraception, Senegal

\section{Introduction}

In Senegal, adolescents aged 10 to 19 years represent $22.9 \%$ of the country's total population. Of these, more than half (54.5\%) are teenage girls [1]. The rate of unmet need for modern contraception remains high among Senegalese women (47.3\%). It is $16.7 \%$ among teenage girls aged 15 - 19 [2]. In general, adolescent girls around the world, especially those in developing countries, are exposed to reproductive health problems and their consequences. Studies in sub-Saharan Africa had shown that girls' enrolment in school was positively associated with contraceptive use among girls at all levels of schooling [3]. The net secondary school enrolment rate increases over the years in Senegal (13.6\% to 32.5\%). However, barriers to adolescents' access to family planning services remain high [4] [5] [6]. In Senegal, few studies have been conducted on the use of modern contraception in schools. The aim of this assessment was to study modern contraceptive practice in schools in Dakar, Senegal, during the year 2018.

\section{Material and Methods}

The study took place in 2 public schools in the city of Dakar in 2018. It was a middle and high school. The Middle School of Grand Yoff was located in the suburban area of Dakar and the high school (Lycée Mixte Maurice Delafosse) was located in the central area of Dakar.

\subsection{Type and Period of Study}

This was a cross-sectional study with an analytical focus. It took place from March 1st to April 30th, 2018.

\subsection{Study Population}

The study population consisted of students from Maurice Delafosse High School and Grand Yoff Middle School.

\section{Inclusion criteria}

Included in the study were students aged 13 to 18 years.

\section{Criteria for non-inclusion}

Adolescents who did not wish to participate in the study.

\subsection{Sampling}

The sample size was calculated on the basis of the proportion of adolescents aged 15 and 18 using contraception, which is $24.7 \%$ according to the 2017 DHS [2] using the simple random sampling method. Two schools (a high school and a middle school) were randomly selected using the ALEA function of Microsoft 
Excel 2018 software. This draw was made on the basis of the list of schools provided by the Dakar Academy Inspectorate. In each school, a captive audience approach was used in the classrooms to identify students who volunteered to participate in the study [7]. Only those who had verbally expressed their consent had received the questionnaire.

Four hundred and fifty-two (452) students participated in the survey. Participants, from the first to the last year of high school, were qualified to participate in the study.

\subsection{Data Collection Procedure Tool}

The questionnaire had been developed by the co-authors. It had been tested in a randomly selected high school. The pre-test involved 40 students. A workshop to correct and validate the questionnaire had been organized by the co-authors. The questionnaire was divided into 3 parts. The first part concerned the description of the respondent and his or her social environment. The second part concerned the sexual behavior of students. The last part concerned knowledge and practices in the field of modern contraception.

These were self-administered questionnaires administered by students. The questionnaire was given to the students by the interviewers. After giving the students filling instructions, they gave them 45 minutes to complete the questionnaires. After the time allowed, the questionnaires were retrieved by the interviewers.

\subsection{Data Analysis}

The data entry was done with the Epi-info version 7 software. The analysis was done with SPSS version 21 software.

The description of the student population was based on their socio-demographic characteristics, their living environment and their access to family planning services.

The analysis had identified factors associated with current use of modern contraceptive methods among students. This use is defined as the use of contraceptive methods in sexual relations between the student and his or her partner (either directly if the student is a girl or indirectly by the partner if the student is a boy).

Dependent variable

In this study, we considered the use of modern contraceptive methods as a dependent variable, which is dichotomous: use (yes $=1$ ) and non-use $($ No $=0)$. By modern contraceptive method, we considered the following methods: condom, pill, injectables (depo-provera), implant, intrauterine device (IUD), emergency contraception.

Independent variables

The explanatory variables were socio-demographic characteristics, their living environment and access to family planning services including information services. $\mathrm{Chi}^{2}$ and Fisher exact to the $5 \%$ risk threshold had been used for the com- 
parison of proportions. The difference was considered significant when $\mathrm{p}<0.05$.

The multivariate analysis examined factors associated with contraceptive use among students. To consider confounding and interaction factors, all variables with p-values less than 0.25 were included in the logistic regression model.

\section{Results}

\subsection{Descriptive Part}

Four hundred and fifty-two (452) students were surveyed.

The average age was 16.3 years with a standard deviation of 1.5 and extremes of 13 to 19 years.

Girls were in the majority (62\%) (see Table 1). The sex ratio was 0.61 .

Distribution of students by sexual activity

Seventy-three percent $(72.72 \%)$ of students who had sex had done so at an age below 16 years with a minimum age of 7 years (see Table 2).

Distribution of students according to contraceptive use

The question about the use of modern contraception was answered by 294 students. Current contraceptive use was reported in 26 students $(8.84 \%)$. The method used was reported in 22 cases. Among the latter 20 students (90.9\%) used condoms and 2 (9.1\%) used the pill (see Table 3).

Table 1. Individual socio-demographic characteristics of students.

\begin{tabular}{ccc}
\hline & Frequency $(\mathrm{n})$ & Percentage $(\%)$ \\
\hline Gender & 278 & 62.05 \\
Female & 170 & 37.95 \\
Male & & \\
Level of study & 308 & 68.90 \\
1st Cycle & 139 & 31.10 \\
2nd Cycle & & \\
Child's source of income & 329 & 72.8 \\
Parents & 21 & 4.6 \\
Friends & 7 & 1.5 \\
Scholarship & 7 & 1.5 \\
Business & 10 & 2.1 \\
Other & &
\end{tabular}

Table 2. Distribution of students according to sexual activity.

\begin{tabular}{ccc}
\hline Existence of sexual intercourse $\mathrm{N}=452$ & Frequency $(\mathrm{n})$ & Percentage $(\%)$ \\
\hline No & 397 & 87.83 \\
Yes & 55 & 12.17 \\
Age of first sexual intercourse N $=55$ & 72.72 \\
Under 16 years of age & 40 & 27.28 \\
Over 16 years of age & 15 & \\
\hline
\end{tabular}


Thirty-five percent of the students did not answer the question.

Reasons for not using contraceptive methods

One hundred and seventy-four (174) students responded regarding the question, why you do not use a contraceptive method.

$52.3 \%$ say they do not have sex, $38.5 \%$ prefer to keep their virginity until the age of marriage and $26.4 \%$ of students associated sex with matrimoniality (see Table 4).

Use of modern contraceptive methods according to family and social environment

Seven percent $(7 \%)$ of the students undergoing family control used modern contraceptive methods (see Table 5).

Twelve percent (11.9\%) of students who belonged to social groups used modern contraceptive methods (see Table 5).

Use of modern contraceptive methods based on knowledge of modern contraceptive methods

Twenty-nine percent (29\%) of students who knew that youth hostels were a means of accessing contraceptives used contraceptive methods (see Table $6)$.

\subsection{Multivariate Analysis}

Age, gender, education level, access to a youth socio-educational home and having a child were the factors associated with the use of modern contraceptive methods among students (see Table 7).

Table 3. Distribution of students by modern contraceptive use $(n=452)$.

\begin{tabular}{ccc}
\hline Student contraceptive use & Frequency $(\mathrm{n})$ & Percentage $\%$ \\
\hline No & 268 & 59.29 \\
Yes & 26 & 5.75 \\
Did not respond & 158 & 34.96 \\
\hline
\end{tabular}

Table 4. Distribution of students by reasons for rejecting modern contraceptive use $\mathrm{n}=$ 174.

\begin{tabular}{lcc}
\hline \multicolumn{1}{c}{ Reasons for not using contraceptive methods } & Frequency (n) & Percentage \% \\
\hline Has never had sex & 91 & 52.3 \\
Prefer to keep virginity & 67 & 38.5 \\
Not yet married & 46 & 26.4 \\
Is ignorant of methods & 12 & 6.9 \\
Believes that methods are harmful to health & 10 & 5.7 \\
Believes that the use of methods is too early for their age & 20 & 11.5 \\
\hline
\end{tabular}


Table 5. Distribution of the use of modern contraceptive methods according to the social and environmental environment.

\begin{tabular}{ccc}
\hline Use of modern contraceptive methods among young people & $\begin{array}{c}\text { Frequency } \\
\mathrm{n}\end{array}$ & $\begin{array}{c}\text { Percentage } \\
\%\end{array}$ \\
\hline Family life with their parents (small family) & 23 & $8.6 \%$ \\
Family life in an extended family & 18 & $12 \%$ \\
Existence of family control of outings & 19 & $7 \%$ \\
Parental education & 21 & $8.8 \%$ \\
Discussion of taboo topics with parents & 14 & $10 \%$ \\
Belonging to social groups & 23 & $11.9 \%$ \\
\hline
\end{tabular}

Table 6. Distribution of contraceptive use according to knowledge of modern contraception and its access routes.

\begin{tabular}{lcc}
\hline \multicolumn{1}{c}{ Use of modern contraceptive methods among young people } & Frequency n & Percentage \% \\
\hline Knowledge of the existence of modern contraceptive methods & 26 & 12.6 \\
$\begin{array}{l}\text { Knowledge of access routes to contraceptive methods: } \\
\text { Health Center }\end{array}$ & 12 & 15.6 \\
$\begin{array}{l}\text { Knowledge of access routes to contraceptive methods: } \\
\text { Private clinic }\end{array}$ & 4 & 11.1 \\
Knowledge of access routes to contraceptive methods: Pharmacy & 20 & 16.7 \\
Knowledge of contraceptive methods: Youth shelter & 9 & 29 \\
Knowledge of methods that protect against HIV & 18 & 17 \\
Knowledge of emergency contraception & 9 & 24.3 \\
\hline
\end{tabular}

Table 7. Factors associated with the use of modern contraception in schools in Dakar.

\begin{tabular}{|c|c|c|}
\hline & p-value & $\operatorname{AR}[95 \% \mathrm{CI}]$ \\
\hline Gender & 0.000 & \\
\hline Male & & $27.8[6.8-100.0]$ \\
\hline Female & & 1 \\
\hline Age group & 0.049 & \\
\hline Under 18 years of age & & 1 \\
\hline Over 18 years of age & & $4.7[1.02-22.5]$ \\
\hline Level of study & 0.004 & \\
\hline $1^{\text {st }}$ cycle & & 1 \\
\hline $2^{\text {nd }}$ cycle & & $10.6[2.1-53.0]$ \\
\hline Knowledge of contraceptive methods access routes: Youth shelter & 0.041 & \\
\hline Yes & & $3.9[1.1-14.9]$ \\
\hline No & & 1 \\
\hline Student with children & 0.009 & \\
\hline Yes & & $25.6[2.2-100.0]$ \\
\hline No & & 1 \\
\hline
\end{tabular}




\section{Discussion}

\subsection{Socio-Demographic Characteristics}

In our study, the average age was 16.3 years with a standard deviation of 1.5 and extremes of 13 to 19 years. In Africa, studies had shown similar results with average ages of modern contraceptive use among young people aged 17 on average [8]. In 2002, the World Health Organization (WHO) studied the sexual trends of 15 -year-old students in 35 countries. The study indicated that the average age of first sexual intercourse in most countries was $16-19$ years for girls and $17-19$ years for boys [9]. This may explain the onset of the need for contraception at these ages.

In our study, the students were mainly under 18 years of age $(71.7 \%)$. The majority of adolescents (98\%) were not on contraception; only $2 \%$ used a contraceptive method. Age was statistically significant for the use of modern contraceptive methods. Adolescents over 18 years of age were 4.7 times more likely to use a contraceptive method than others $(\mathrm{AR}=4.7,95 \% \mathrm{CI}[1.02-22.5])$.

\subsection{Gender Influence on the Use of Contraceptive Methods}

In our study, girls accounted for $62.1 \%$ of the sample. The majority of girls (98.4\%) were not on contraception, only $22.1 \%$ of boys used a modern contraceptive method. In 2002, the World Health Organization (WHO) studied the sexual trends of 15 -year-old students in 35 countries. The study showed that the percentage of boys having sex was often higher than that of girls [9].

In Senegal, another study had shown, as ours did, that men were more involved in modern contraceptive practice than women [10]. Indeed, more of them used the male condom but also emergency contraception for their sexual partner. In this study, boys were 28 times more likely to use a contraceptive method than girls ( $\mathrm{AR}=27.8 ; 95 \% \mathrm{CI}$ : 6.8 - 100). These results are similar to those found in Ethiopia, where boys were more likely to have sex (65\%) than girls [8].

Elsewhere, in other contexts in Europe, it has been noted that young women are more likely to use modern contraceptive methods than those in less developed countries such as those in sub-Saharan Africa [11].

However, in other countries such as Thailand, a study has highlighted the emergence of a new form of sexuality for young girls in schools who tend to take responsibility for their sexual activity by deciding for themselves [12]. The gender difference in contraceptive use and sexual involvement is explained in some studies by socio-cultural and religious considerations [13]. Senegal is still a country subject to strong religious and traditional influences. Thus, Senegalese social norms lead Senegalese women to be reluctant to declare that they are concerned about sexuality and aspects related to contraception or sexual protection [14].

\subsection{Influence of Education Level on Contraceptive Use}

The students were between 13 and 18 years old (average 16.3 years). $68.9 \%$ of the 
students were in the first cycle and $31.1 \%$ in the second cycle. Twenty-three (20.7\%) of the respondents had heard of at least one contraceptive method. There was a statistically significant relationship between education level and use of modern contraceptive methods ( $\mathrm{p}<0.05)$. The male condom was the method most known by the students. Few students (14.9\%) were familiar with modern methods. Contraceptive use was more frequent among second cycle students (20.7\%) than among first cycle students (1.7\%).

A study in Niger showed that contraceptive use was more frequent among first-cycle students (64.5\%) than among second-cycle students $(35.5 \%)(\mathrm{p}<$ $0.05)$ [15]. Unlike in Tunisia, women's educational level was significantly associated with contraceptive use. This finding could be explained by the fact that educated women were better informed about different contraceptive methods [16].

According to the Demographic and Continuous Health Survey in 2014, modern or traditional contraceptive prevalence increases sharply with education level. For modern methods, prevalence increases from $14 \%$ among women with no education to $29 \%$ among those with primary education and 33\% among women with medium/secondary education or higher [17].

\subsection{Influence of Knowledge on the Use of Contraceptive Methods}

The impact of knowledge acquisition on the use of contraceptive methods has been proven by numerous studies [18]. In middle and high schools in Dakar, few students have any knowledge of contraceptive methods (12.6\%). There is also a lack of knowledge among students of how to access modern contraceptive methods.

However, students who know that youth hostels in schools are a place where contraceptive methods can be obtained are 3.9 times more likely to use contraceptive methods AR $=3.9,95 \%$ CI [1.1 - 14.9]. Youth hostels are socio-educational hostels in middle and high schools in Senegal with, among other roles, a role of peer education and the provision of contraceptive methods.

This result reflects the importance of introducing sexual health interventions for students in schools. Studies had shown similar results and highlighted the importance of sexual health interventions in schools [19]. In a study conducted in 25 African countries, it was pointed out that facilitating access to contraceptive methods in schools has an impact on reducing unwanted pregnancies [20]. Studies have shown that young people's sexuality is better addressed by health policies when sex outside marriage is recognized, accepted and regulated rather than prohibited in all contexts outside marriage [21].

Youth hostels in schools with their permissive character contribute to the democratization of young people's sexual choices.

\subsection{Influence of Student Parity on the Use of Modern Contraceptive Methods}

It is widely accepted that modern contraception has reduced teenage pregnan- 
cies [22]. However, the question addressed by this study is whether the occurrence of pregnancy in a teenager may lead him or her to use contraceptive methods for future sexual intercourse. In schools in Dakar, the study showed a statistically significant link between having a child and the use of modern contraceptive methods ( $A R=25.6,95 \%$ CI $[2.2-100.0]$ ). Students who had a child were $25.6 \%$ more likely to use a contraceptive method. This attitude could be explained by the implementation of strategies to avoid further unwanted pregnancies by adolescents. Indeed, unwanted pregnancies can have disastrous consequences for teenage girls and their families [23]. Contraceptive use is part of strategies to avoid pregnancy [24].

\section{Conclusion}

In Senegal, the issue of addressing the sexual health needs of adolescents remains a concern. This study highlighted the importance of age in the use of contraception. This age here was over 18 years despite the existence of sexual intercourse from the age of 7 . This study showed that boys were more likely to use contraceptive methods. The added value of this study lies in the fact that it showed the importance of socio-educational homes in schools. Students attending these homes were 3.9 times more likely to use a contraceptive method. Thus, this study suggests a need for better targeting in behavior change communication for better responsibility in the management of their sexual health. This targeting will involve better recruitment of girls, young people under 18 years of age. This study suggests that socio-educational homes in schools and peer education, especially for young female mothers, could be the gateway to communication strategies. Indeed, these young girls had shown that they had developed protection strategies through better use of modern contraceptive methods in their sub-populations.

\section{Limitations}

The limitations of this study are related to the use of self-administration of questions. This method was responsible for a low response rate for some questions (e.g. contraceptive use response rate $65.04 \%$ out of a total of 452 students). However, this strategy had resulted in greater respect for the privacy and confidentiality rights of adolescents.

\section{Ethics}

This study had received the approval of the Ethics Committee of the Cheikh Anta Diop University of Dakar No. 033s/201s/CER/UCAD.

It has also been approved by the Ministry of Education (No.

1621/MEN/SG/DCMS/aad) and has been monitored in its implementation through the School Medical Control Division of the Ministry of Education.

The authorization of the heads of the institutions was obtained before the start of the study. 
Free and informed consent was obtained from students. In addition, they were free not to participate in the study.

\section{Conflicts of Interest}

The authors declare no conflicts of interest regarding the publication of this paper.

\section{References}

[1] République du Sénégal. Ministère de l'économie, des finances et du plan (2018) Population du Sénégal en 2017/MEFP/ANSD mars 2018.

[2] Agence Nationale de la Statistique et de la Démographie (ANSD) [Sénégal], et ICF (2018) Sénégal: Enquête Démographique et de Santé Continue (EDS-Continue 2017). ANSD et ICF, Rockville.

[3] Ainsworth, M., Beegle, K. and Nyamete, A. (1996) The Impact of Women's Schooling on Fertility and Contraceptive Use: A Study of Fourteen Sub-Saharan African Countries. The World Bank Economic Review, 10, 85-122. https://doi.org/10.1093/wber/10.1.85

[4] Agence Nationale de la Statistique et de la Démographie (ANSD) [Sénégal], et ICF (2006) Sénégal: Enquete Démographique et de Santé Continue (EDS 2005). ANSD et ICF, Rockville.

[5] Agence Nationale de la Statistique et de la Démographie (ANSD) [Sénégal], et ICF (2017) Sénégal: Enquete Démographique et de Santé Continue (EDS-Continue 2016). ANSD et ICF, Rockville.

[6] Naré, C., Katz, K. and Tolley, E. (1997) Adolescents' Access to Reproductive Health and Family Planning Services in Dakar (Senegal). African Journal of Reproductive Health, 1, 15-25. https://doi.org/10.2307/3583373

[7] Sedgwick, P. (2013) Convenience Sampling. BMJ, 347, f6304. https://doi.org/10.1136/bmj.f6304

[8] Bisrat, F. and Pickering, J. (1994) High School Students' Knowledge, Attitude and Practice of Contraception in Harer Town, Eastern Ethiopia. Ethiopian Medical Journal, 32, 151-159.

[9] Curry, C., Roberts, C., Morgan, A., Smith, R., Settertobulte, W., Samdal, O., et al. (2004) OMS/Europe, La santé des jeunes en contexte Enquête sur les comportements liés à la santé des enfants en âge scolaire (HBSC): Rapport international de l'enquête réalisée en 2001/2002. OMS, Danemark.

[10] Doucoure, R.H. (2015) Connaissances, attitudes et pratiques de la contraception et de la prévention des infections sexuellement transmissibles en milieu estudiantin: Enquête chez les étudiant(e)s de l'Université Cheikh Anta Diop de Dakar/Sénégal. Mémoire pour l'obtention du diplôme d'études spéciales (D.E.S.) de gynécologie-obstétrique. Université Cheikh Anta Diop de Dakar, Dakar, No. 124.

[11] Bearinger, L.H., Sieving, R.E., Ferguson, J. and Sharma, V. (2007) Global Perspectives on the Sexual and Reproductive Health of Adolescents: Patterns, Prevention, and Potential. The Lancet, 369, 1220-1231. https://doi.org/10.1016/S0140-6736(07)60367-5

[12] Vuttanont, U., Greenhalgh, T., Griffin, M. and Boynton, P. (2006) "Smart Boys" and "Sweet Girls"-Sex Education Needs in Thai Teenagers: A Mixed-Method Study. The Lancet, 368, 2068-2080. https://doi.org/10.1016/S0140-6736(06)69836-X 
[13] Aras, S., Orcin, E., Ozan, S. and Semin, S. (2007) Sexual Behaviors and Contraception among University Students in Turkey. Journal of Biosocial Science, 39, 121-135. https://doi.org/10.1017/S0021932006001258

[14] Lagarde, E., Enel, C., Seck, K., Gueye-Ndiaye, A., Piau, J.P., Pison, D.V., Ndoye, I. and Mboup, S. (2000) Religion and Protective Behaviours towards AIDS in Rural Senegal. Epidemiology \& Social, 14, 2027-2033. https://doi.org/10.1097/00002030-200009080-00019

[15] Anochie, I. and Ikpeme, E. (2003) La connaissance, l'attitude et l'utilisation de la contraception chez les filles du secondaire à Port Harcourt. Niger. J Med., 12, 217-220.

[16] Dimassi, K., Douik, F., Douzi, M.A., et al. (2016) Les déterminants sociaux de l'utilisation des méthodes contraceptives en Tunisie. Revue d'Epidémiologie et de Santé Publique, 65, 53-59. https://doi.org/10.1016/j.respe.2016.06.330

[17] Agence Nationale de la Statistique et de la Démographie (ANSD) [Sénégal], et ICF (2015) Sénégal: Enquête Démographique et de Santé Continue (EDS-Continue 2014). ANSD et ICF, Rockville.

[18] Pazol, K., Zapata, L.B., Tregear, S.J., Mautone-Smith, N. and Gavin, L.E. (2015) Impact of Contraceptive Education on Contraceptive Knowledge and Decision Making: A Systematic Review. American Journal of Preventive Medicine, 49, S46-S56. https://doi.org/10.1016/j.amepre.2015.03.031

[19] Kirby, D.B., Laris, B.A. and Rolleri, L.A. (2007) Sex and HIV Education Programs: Their Impact on Sexual Behaviors of Young People throughout the World. Journal of Adolescent Health, 40, 206-217. https://doi.org/10.1016/j.jadohealth.2006.11.143

[20] Longwe, A. and Smits, J. (2011) The Impact of Family Planning on Primary School Enrolment in Sub-National Areas within 25 African Countries. African Journal of Reproductive Health, 17, 23-38.

[21] Weaver, H., Smith, G. and Kippax, S. (2005) School-Based Sex Education Policies and Indicators of Sexual Health among Young People: A Comparison of the Netherlands, France, Australia and the United States. Sex Education, 5, 171-188. https://doi.org/10.1080/14681810500038889

[22] Amsellem-Mainguy, Y. (2011) Contraception et grossesses à l'adolescence: Vers une reconnaissance du droit à l'intimité des jeunes. Informations Sociales, 165-166, 156-163.

[23] Singh, S., Gilda, S.G. and Hussain, R. (2010) Unintended Pregnancy: Worldwide Levels, Trends, and Outcomes. Studies in Family Planning, 41, 241-250. https://doi.org/10.1111/j.1728-4465.2010.00250.x

[24] Nebié, Y., Meda, N., Leroy, V., Mandelbrot, L., Yaro, S., Sombié, I., et al. (2001) Sexual and Reproductive Life of Women Informed of Their HIV Seropositivity: A Prospective Cohort Study in Burkina Faso. Journal of Acquired Immune Deficiency Syndromes, 28, 367-372. https://doi.org/10.1097/00126334-200112010-00010 